Slavica

bruxellensia

\section{Slavica bruxellensia}

Revue polyphonique de littérature, culture et histoire

slaves

$10 \mid 2014$

Espace slave, espace germanique

\title{
Ray M. Douglas, Les expulsés
}

\section{Laurent Béghin}

\section{OpenEdition \\ Journals}

Édition électronique

URL : http://journals.openedition.org/slavica/1562

DOI : 10.4000/slavica.1562

ISSN : 2034-6395

Éditeur

Université libre de Bruxelles - ULB

\section{Référence électronique}

Laurent Béghin, «Ray M. Douglas, Les expulsés », Slavica bruxellensia [En ligne], 10 | 2014, mis en ligne le 10 février 2014, consulté le 22 septembre 2020. URL : http://journals.openedition.org/slavica/1562 ; DOI : https://doi.org/10.4000/slavica.1562

Ce document a été généré automatiquement le 22 septembre 2020.

\section{(c) (i) () $\Theta$}

Les contenus de Slavica bruxellensia sont mis à disposition selon les termes de la Licence Creative Commons Attribution - Pas d'Utilisation Commerciale - Pas de Modification 3.0 France. 


\section{Ray M. Douglas, Les expulsés}

\section{Laurent Béghin}

\section{RÉFÉRENCE}

Ray M. Douglas, Les expulsés, traduit de l'anglais par Laurent Bury, Flammarion, coll. « Au fil de l'histoire », Paris, 2012, 510 p. 
La géographie humaine de l'Europe centrale et orientale subit de profondes transformations au cours des années qui suivirent la Seconde Guerre mondiale. La modification des frontières de nombreux États provoqua d'importants transferts de populations: Polonais des Confins, Ukrainiens de Petite Pologne, Italiens d'Istrie ${ }^{1}$ et surtout les millions d'Allemands ethniques établis depuis des siècles en dehors des frontières actuelles de la République fédérale d'Allemagne. De 1945 au début des années 1950, entre douze et quatorze millions de Volksdeutsche furent contraints de quitter leur foyer souvent dans des conditions inhumaines. Ces expulsions, qui firent entre cinq cent mille et un million et demi de victimes et qui constituent « peut-être la plus grande migration dans l'histoire de l'humanité » (p.9), sont au centre de

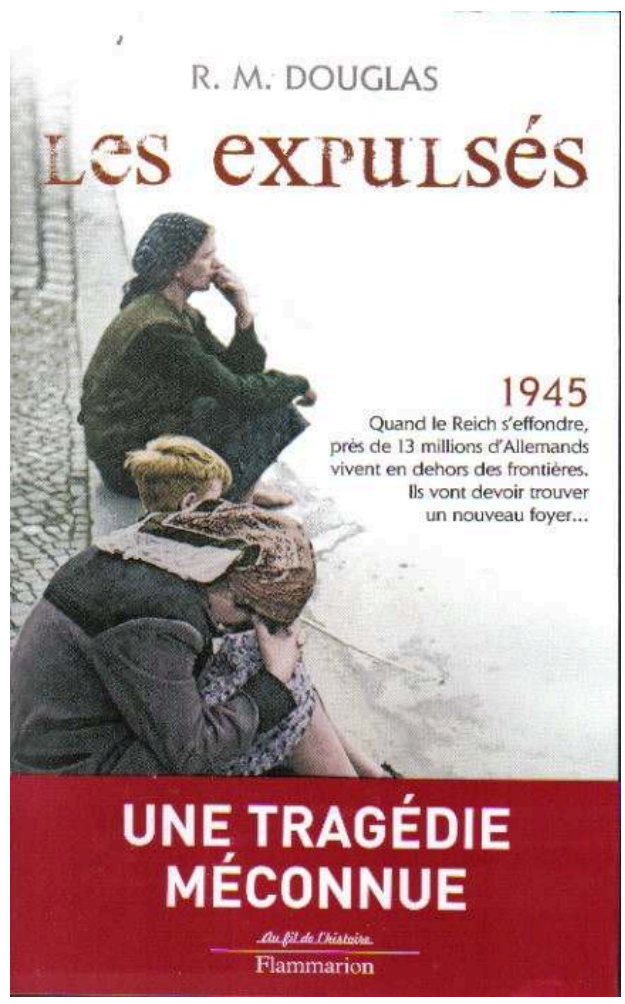
l'ouvrage de Ray M. Douglas².

Professeur d'histoire à la Colgate University (Hamilton, État de New York), l'auteur étudie les différents aspects de cette tragédie. Née en pleine guerre dans l'entourage du président tchécoslovaque en exil Edvard Beneš (ch. 1), l'idée de déporter les Allemands ethniques fut appliquée aussitôt après la capitulation du Reich (ch. 3). La Tchécoslovaquie s'empressa de se débarrasser de près de trois millions d'Allemands des Sudètes. En Pologne, à « la mi-juin [1945], les routes situées entre les Territoires reconquis et l'Oder étaient noires d'Allemands " (p. 128). Les transferts de populations étaient souvent précédés par le regroupement forcé des individus à expulser. Certains camps nazis, comme Majdanek ou Auschwitz, furent même réutilisés (ch. 5). Ironie du sort: il arriva qu'on arrêtât comme Allemands ethniques des Juifs au motif qu'ils étaient germanophones! Ces déportations, qui concernèrent aussi la Hongrie, la Yougoslavie et la Roumanie et qui s'accompagnèrent souvent d'exactions (notamment à Ústí nad Labem - Aussig en allemand -, dans le nord-ouest de la Bohême, où, le 31 juillet 1945, entre cent et cent cinquante Volksdeutsche, dont un nouveau-né, furent massacrés par des Tchèques), furent présentées par les gouvernements des pays concernés comme une explosion spontanée de la juste colère des populations contre des minorités allemandes qui, pendant l'Occupation, avaient pu jouir d'une situation privilégiée. L'auteur montre que, la plupart du temps, ces «expulsions sauvages » furent en réalité soigneusement encadrées par les autorités, celles-ci espérant mettre les Alliés devant le fait accompli. À vrai dire, gagnés aux thèses de Beneš, les vainqueurs avaient eux aussi décidé de vider l'Europe centrale de ses Allemands ethniques. Selon l'article 13 des accords de Postdam, signés le 2 août 1945, les gouvernements britannique, américain et soviétique reconnaissaient « qu'il y aura lieu de procéder au transfert en Allemagne des populations allemandes restant en Pologne, en Tchécoslovaquie et en Hongrie ». Le document stipulait par ailleurs que ces transferts 
devraient «être effectués de façon ordonnée et humaine ». Il s'agissait là d'un vœu pieux car les Alliés, dont Douglas pointe à plusieurs reprises la responsabilité morale, ne prirent jamais la moindre mesure pour atténuer les souffrances que devait immanquablement occasionner le déplacement de millions de personnes. Au bout du compte les «expulsions organisées » des années 1946-1947 (ch.6) ne furent pas moins chaotiques et meurtrières que les déportations de l'été 1945. Parmi leurs victimes, on compte beaucoup d'enfants, auxquels l'auteur consacre une section de son livre (ch. 8). Souvent parqués dans des camps à leur arrivée en Allemagne, parfois méprisés par la population locale, les Volksdeutsche s'adaptèrent difficilement à leur nouveau pays (ch. 11).

Le repeuplement des territoires autrefois habités par des Allemands ethniques fut tout aussi problématique. Attirés par la richesse de ce nouveau Far West vantée par la propagande officielle, les colons déchantaient vite et ne tardaient pas à repartir (emportant parfois avec eux des objets laissés par les Allemands). Les conséquences démographiques et économiques des expulsions se font sentir jusqu'à nos jours. Aujourd'hui encore " la majorité des zones de Pologne occidentale d'où les Allemands avaient été chassés comptent (...) parmi les moins densément peuplées du pays et les plus attardées sur le plan économique » (p. 313).

Dans le dernier chapitre de l'ouvrage, Douglas s'interroge sur le sens et la mémoire de cet épisode (ch. 13). En dehors de la RFA des années 1950, où l'insistance sur les souffrances endurées par l'Allemagne pendant et après la guerre servait à occulter le mal que les Allemands avaient infligé au reste de l'Europe, en particulier à la population juive, l'expulsion des Volksdeustche ne suscitait au mieux que de la condescendance. «Parmi les exemples de violation massive des droits humains dans les temps modernes, c'est le seul cas où l'on a affirmé qu'il valait mieux passer sous silence l'événement de peur d'amoindrir l'horreur que devait inspirer un crime plus grand" (p. 382). C'est l'un des principaux mérites de ce livre, qui, pour échapper au discours victimaire, s'appuie essentiellement sur des archives officielles, de montrer que, loin de punir des criminels de guerre, les expulsions frappèrent le plus souvent des femmes, des enfants et des vieillards innocents. Un bémol toutefois: quelques cartes supplémentaires (l'ouvrage en compte une seule, celle des camps par lesquels transitèrent les expulsés) auraient permis aux lecteurs de cette étude de mieux saisir l'ampleur des transferts.

\section{NOTES}

1. Sur les transferts de populations polonaises et ukrainiennes, on lira Timothy Snyder, The Reconstruction of Nations: Poland, Ukraine, Lithuania, Belarus, 1569-1999 (La reconstruction des nations : Pologne, Ukraine, Lituanie, Bélarus, 1569-1999), Yale University Press, Yale, 2003, 384 p. Sur les Italiens d'Istrie, voir Raoul Pupo, Il lungo esodo. Istria: le persecuzioni, le foibe, l'esilio (Le long exode. Istrie : les persécutions, les foibe, l'exil), Rizzoli, Milan, 2005, 333 p.

2. Version originale : Orderly and Humane. The Expulsion of the Germans after the Second World War, Yale University Press, New Haven, 2012, 416 p. 
INDEX

Mots-clés : Europe centrale, Europe orientale

\section{AUTEURS}

LAURENT BÉGHIN

Institut libre Marie Haps 